\section{Female Japanese scientist wins harassment case}

In a landmark case, a Japanese court has ruled that a female academic researcher was the victim of harassment and should beawarded compenstion. Kumiko Ogoshi, a research assistant at Nara Medical

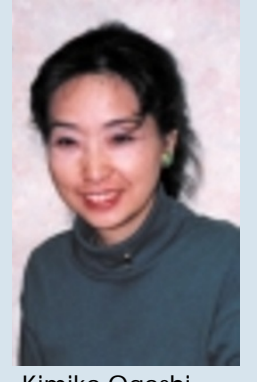
Kimiko Ogoshi University, has been awarded 550,000 yen (US $\$ 5,100$ ) by the Osaka District Court for inappropriate interference and harassment by her superior, a male professor.

Ogoshi filed suit in 1997, alleging that the professor, head of the university's department of public health, had bullied her for years and tried to make her resign. She claimed he had moved her belongings out of her office and fouled it with liquid waste while she was away. She says he also refused to sign papers necessary for her to complete her research or to go to scientific meetings.

Ogoshi specializes in the health effects of trace elements, and joined Nara Medical University as a research associate in 1976, but was never promoted. Currently, there is one other woman in the five-person department, an associate professor. She says the harassment did not begin until 1993, due she believes, to her joining the Association of Research Associates, a group formed to include instructors and associates in faculty gatherings.

She had petitioned for 5.5 million yen in compensation and told Nature Medicine that she is appealing the judgment from her local govemment, the Nara Prefecture, which employs University staff.

The Japanese Prime M inister's Office for Gender Equality estimates that in 1997, women comprised only $12.3 \%$ of fulltime teachers at universities, and this is the first time that a case of academic harassment, or akahara, has been ruled in favor of a plaintiff, says Ogoshi. The idea that both men and women can speak out against harassment is gaining ground in Japan. The case of a male academic who claims harassment by Ryuku University in Okinawa is presently being heard in Naha District Court.

Alicia Ault, Washington D.C.

\section{NIH spending in developing countries increases}

According to new figures from the Fogarty International Center (FIC), the branch of the National Institutes of Health (NIH) in charge of coordinating foreign research efforts, NIH spent $\$ 272$ million abroad in fact, the fiscal year 1999 saw the largest increase in domestic grants with foreign components for 25 years. While the big money still goes to developed countriescollaborations with Canada amounted to $\$ 14$ million-liaisons with developing countries are on the increase. Malaysia, for example, benefited from $\$ 1$ million of NIH money in 1999 against only \$4,000 1997. Comparative sums for Zimbabwe are $\$ 3$ million and $\$ 324,000$.

There appears to be confusion, however, over precisely what is covered with $\mathrm{NIH}$ funding to foreign institutions. Direct costs are permitted, but indirect are not. Just what indirect and direct costs are is not clear, says Ray Loomis, director of fiscal affairs in the Department of Microbiology and Tropical Medicine at George Washington University Medical Center.

Loomis explains that direct costs include travel, long distance telephone calls and faxes, but not rental of the telephone lines. Indirect costs include electricity, purchasing services and rent for laboratory space. However, for an off-campus site, telephone lines, rent, and electricity could be consid1999, up from $\$ 204$ million in 1997. In ered direct costs. Such is the confusion that an NIH committee, led by NIH deputy director for Extramural Research, Wendy Baldwin and FIC director, Gerald Keusch, is investigating the spending policy.

James Kazura of Case Western Reserve University notes that his university has the largest amount of NIH funding for overseas extramural research. He studies filariasis and malaria in Kenya and Papua New Guinea and explains that whereas an NIH grant may cover the cost of an expensive piece of equipment, such as a liquid scintillation counter, no overhead is allowed for maintainance the equipment. His group's work to develop a malaria vaccine in Kenya was interrupted recently because of a powercut, yet for a $\$ 100,000$ investment in a generator and an additional $\$ 50,000$ in petroleum, research would not have stopped. Such expenses, however, are not currently allowed under NIH rules.

Some groups that promote research in foreign countries have now picked up on the issue. Greg Gonsalves, policy director of the Treatment Action Group, an AIDS advocacy group, is drafting a letter to Health and Human Services Secretary, Donna Shalala, to plead that NIH be allowed to alter its policy and fund overheads in collaborating countries as a means of strengthening infrastructure.

Myrna E. Watanabe, Connecticut

\section{Finally, a plan to reduce measles deaths}

After years of stagnation and disagreement, leading public health agencies last month drew up a joint plan to tackle measles, which kills some 880,000 children a year-more than any other vaccine-preventable disease. The plan, produced by the World Health Organization (WHO) and UNICE, in collaboration with the US Centers for Disease Control and Prevention $(C D C)$ and others, aims to cut measles deaths worldwide by two-thirds between now and 2005 , and thereafter to prevent 600,000 deaths per year.

Efforts to control measles have been hampered by a paralyzing debate among public health bodies and funding agencies — not over the need to save lives, but over the question of whether measles can or should be eradicated. By postponing any decision on eradication until after 2005, and focusing instead on reducing the death toll, the parties have managed to reach consensus.

Since most developing countries' already-overstretched immunization programs are fully focused on polio eradication, it was argued that a second eradication campaign was not feasible.

However, the pressure to act has been growing because of serious outbreaks of the disease. Half of the total deaths are concentrated in just four countries, the Democratic Republic of Congo, Ethiopia, India and Nigeria.

The new plan aims to help countries with a high measles burden reach $80 \%$ of each year's birth cohort with one dose of measles vaccine. Countries are then advised to provide a second immunization opportunity.

Ana Maria Henao-Restrepo at WHO, who coordinates the agency's measles activities, says that this second "opportunity" was not thought necessary in the past but is now recognized to be essential if death rates are to fall. The vaccine costs just 26 cents and the estimated cost of increasing coverage to $80 \%$ in the 20 countries with the highest measles burden is $\$ 150$ million a year.

Phyllida Brown, Exeter 